\title{
Auditoría interna en el marco de la empresa privada costarricense
}

\section{Internal auditing within the framework of Costa Rican private enterprises}

\author{
DOI: $10.22458 /$ rna.v12i1.3513
}

\author{
M.A.E. Geiner Mora Miranda ${ }^{1}$ \\ ${ }^{1}$ Universidad Fidélitas, Escuela de Contaduría Pública, San José, Costa Rica; \\ gmora@ufidelitas.ac.cr, https://orcid.org/0000-0002-0249-8055; \\ avalverde@ufidelitas.ac.cr, https://orcid.org/0000-0001-7469-9377
}

M.A.F. Ana Patricia Valverde Jiménez ${ }^{1}$

\section{RESUMEN}

La auditoría tanto interna como externa, el control interno, la gestión de riesgos y el gobierno corporativo han evolucionado en la consecución de estrategias que contribuyan eficientemente a lograr los objetivos organizacionales. En esta investigación se analiza la unidad de auditoría interna en las empresas privadas costarricenses. Este estudio se realiza mediante una revisión cuantitativa de los siguientes criterios: normativa vigente, control interno, gestión del riesgo empresarial, gobierno corporativo. El objetivo consiste en determinar la percepción que tiene el sector empresarial a nivel nacional acerca de la necesidad de contar con los servicios de un auditor interno.

\section{ABSTRACT}

Internal and external auditing, internal control, risk management and corporate governance have evolved in the search for better strategies that contribute efficiently to the achievement of organizational objectives. This research analyzes the internal auditing unit in private Costa Rican enterprises. This study consists of a quantitative review of the following criteria: governing regulations, internal control, business risk management and corporate governance. The objective is to determine the perception of the business sector at the national level regarding the need to count on an internal auditor.

\section{RÉSUMÉ}

L'audit interne et externe, le contrôle interne, la gestion de risques et le gouvernement corporatif ont évolué pour obtenir des stratégies qui contribuent efficacement à atteindre les objectifs organisationnels. Cette recherche analyse l'unité d'audit interne dans les entreprises privées costariciennes. Cette étude est réalisée au moyen d'une révision quantitative des critères suivants : réglementation en vigueur, contrôle interne, gestion du risque des entreprises, gouvernement corporatif. L'objectif est de déterminer la perception du secteur des entreprises au niveau national sur la nécessité de disposer des services d'un auditeur interne.

\section{RESUMO}

A auditoria tanto interna quanto a externa, o controle interno, a gestão de riscos e a governança corporativa têm evoluído na realização de estratégias que contribuam de forma eficiente para o alcance dos objetivos organizacionais. Nesta pesquisa analisa-se a unidade de Auditoria Interna em empresas privadas da Costa Rica, estudo que se realiza por meio de uma revisão quantitativa dos seguintes critérios: normas que os regem, controle interno, gestão do risco empresarial, governança corporativa e tem como objetivo determinar a percepção que o setor empresarial tem a nível nacional da necessidade de contar com os serviços de um auditor interno.
PALABRAS CLAVE:

AUDITORÍA INTERNA, GESTIÓN DEL RIESGO, CONTROL INTERNO, GOBIERNO CORPORATIVO
KEYWORDS:

INTERNAL AUDITING, RISK MANAGEMENT, INTERNAL CONTROL, CORPORATIVE GOVERNMENT.
MOTS-CLES:

AUDIT INTERNE, GESTION DU RISQUE, CONTROLE INTERNE, GOUVERNEMENT CORPORATIF.
PALAVRAS CHAVE:

AUDITORIA INTERNA, GESTÃO DO RISCO, CONTROLE INTERNO, GOVERNANÇA, CORPORATIVA. 


\section{INTRODUCCIÓN}

La Auditoría Interna en el marco de la empresa privada se encuentra inmersa en un entorno complejo y cambiante ante las exigencias del modelo de negocio actual que definen el sector empresarial. Por lo que se ha tenido que fortalecer el control interno para gestionar los riesgos potenciales en toda su cadena de valor, así como exigir mayores requerimientos de información tanto de su mercado externo como interno, que permita dar respuesta oportuna en su quehacer a los diversos grupos de interés directos.

Para el desempeño de la labor profesional en el campo de la Auditoría se debe obtener un entendimiento de los factores relevantes de la industria, de regulación y otros factores externos, incluyendo el marco de referencia de información financiera aplicable. Según la NIA 315 Entendimiento de la entidad y su entorno y evolución de los riesgos de representación errónea de importancia relativa: La naturaleza de la entidad se refiere a las operaciones, su propiedad, gobierno corporativo, a los tipos de inversión que está realizando y a sus planes a futuro.

De acuerdo a las Normas Internacionales de Auditoría (2016), estos factores incluyen condiciones de la industria, tales como el entorno competitivo, las relaciones con proveedores, clientes, desarrollos tecnológicos y su entorno de regulación. Así como la medición del desempeño financiero de la entidad y el entendimiento del sistema de control interno. (p. 271)

La investigación tiene como objetivo que el lector sume conocimiento del campo profesional del Contador Público al reconocer y entender las características como: aptitud, cuidado profesional, conocimiento en materia de riesgos, evolución del control interno y gobierno corporativo que hace al auditor interno en un gran asesor de confianza que ayuda (de forma objetiva e independiente) a las empresas a lograr sus objetivos estratégicos y en la mejora de sus operaciones.

De acuerdo con el Informe de Competitividad Global del Foro Económico Mundial (2017-2018), ante los altos niveles de competitividad a las que se afrontan las empresas privadas en Costa Rica, se hace necesario que sus administradores recurran al apoyo que ofrecen las personas profesionales en el campo de la Contaduría Pública.

Esta investigación permitirá discernir si el trabajo de una unidad de auditoría interna debe ser realizado por personas que llevan a cabo otras actividades operativas de línea dentro de la organización o si se requiere de personal profesional dedicado exclusivamente a actividades propias de la unidad de auditoría.

El papel del auditor interno ha evolucionado ante las exigencias propias de los negocios, por lo que es necesario conocer la opinión de los representantes o propietarios de las organizaciones del sector privado, acerca de la formación académica y experiencia en el campo profesional de la auditoría.

Como lo afirma Villavicencio (2017), el auditor interno debe ser un promotor de cambio en las organizaciones, es determinar y garantizar una revisión suficiente y consistente de actividades, flujos de información, con la finalidad de identificar duplicidad de funciones, reprocesos que permitan generar recomendaciones y demostrar los beneficios que generan su labor y lograr los objetivos trazados. (p.42) 


\section{MARCO REFERENCIAL}

\section{Antecedentes de la auditoría interna en Costa Rica}

Con la creación del Colegio de Contadores Públicos, mediante la Ley No. 1038 de 1947, la auditoría comienza a desarrollar procedimientos y normas para uniformar el trabajo realizado por los auditores. El Boletín de Consultoría Gerencial de la PricewaterhouseCoopers Costa Rica (2015), sostiene que esos procedimientos y normas se convirtieron en las guías para aplicar procesos monótonos con una aplicación limitada en la realidad de los negocios.

Menciona el artículo de la PricewaterhouseCooper (2015) que las unidades de auditoría sehan transformado, dando un aporte significativo a las empresas. Esto gracias a la confianza que han colocado la junta directiva y la alta gerencia de las organizaciones a esta unidad.

La implementación de la tecnología en la elaboración de pruebas de cumplimiento permite identificar errores, riesgos, reducir costos en el proceso de toma de decisiones. También, ha permitido que se dé una participación proactiva y no correctiva como en ocasiones ocurría y se ha generalizado como la función que debe tener la unidad de auditoría interna.

Esto ha cambiado con los años en cuanto a que se anticipa al riesgo dando un valor agregado al negocio y no como ocurría anteriormente en que la unidad era partícipe después de haber ocurrido el evento, de acuerdo a lo que señala el Boletín de Consultoría Gerencial (2015).

La visión de la unidad no solo va a las operaciones contables sino más allá, en cuanto a aspectos administrativos para la integración de la eficiencia y eficacia de las operaciones, el cumplimiento de procedimientos, leyes y normativas aplicables, para que así el control interno opere a niveles de una mayor eficiencia en la organización.

Esta investigación permitirá conocer de primer orden el criterio del sector empleador, en cuanto a las exigencias del mercado laboral que deben de estar presente en los profesionales en el campo de la auditoría interna.

\section{Auditoría interna}

\section{Origen}

La auditoría interna desde el siglo XX ha sido visualizada por las organizaciones como una actividad profesional de aseguramiento y respaldo a la dirección, tarea que ha sido desarrollada desde siglos y que se ha acentuado en el nuevo milenio ante las disrupciones con el impacto global derivado de las continuas innovaciones tecnológicas. El rol del auditor interno ha pasado de ser un revisor de los sistemas de la empresa, de la información contable para transformarse en un asesor de la dirección y del gobierno corporativo en materia de la gestión, seguimiento de la estrategia y continuidad empresarial y su sostenibilidad.

\section{Definición}

Sandoval (2012), señala que auditoría interna "en su acepción más amplia, significa verificar que la información financiera, administrativa y operacional que genera una entidad es confiable, veraz y oportuna” (p.28). Es decir, consiste en revisar que los hechos, fenómenos y operaciones se den en la forma en que fueron planeados; que las políticas y lineamientos establecidos se hayan observado y respetado; que se cumple con las obligaciones fiscales, jurídicas y reglamentarias en general.

Para Mendívil (2016) la auditoría interna es desarrollada por profesionales que laboran en la organización; con la finalidad de verificar el cumplimiento de los programas operativos de la empresa.

Según el Instituto de Auditores Internos -IIA por sus siglas en inglés- (2017), la auditoría interna se define como:

Una actividad de aseguramiento y consultoría objetiva e independiente diseñada para agregar valor y mejorar las operaciones de una organización, ayudando a la organización a alcanzar sus objetivos aportando un enfoque sistemático y disciplinado con el fin de evaluar y mejorar la eficacia de los procesos de gestión de riesgos, control y gobierno. (p.1) 
Las definiciones anteriores van más allá de su definición tradicional de auditoría y conlleva a las actividades de verificación, examen, evaluación, contraste de información con la normativa para que esta sea confiable, veraz, oportuna y que la realidad de los hechos se hayan dado conforme fueron planeados.

\section{Competencias}

El éxito de una auditoría interna depende en gran medida de las competencias y habilidades presentes en un auditor, referidas en el conocimiento, experiencia y características personales en el desempeño de su profesión.

Alles (2015), define el concepto competencia como: "las características de personalidad, devenidas en comportamientos, que generaran un desempeño exitoso en un puesto de trabajo" (p.18).

En todo tipo de trabajo son necesarios los conocimientos y las competencias. Sin el conocimiento no es posible realizar un trabajo asignado y su desempeño requiere de las competencias necesarias para dicha función.

Frett (2016), señala que el auditor interno debe desarrollar competencias para lograr un desempeño extraordinario, entre ellas:

- Liderazgo.

- Profesionalismo.

- Conocimientos profundos del sector que opera su organización.

- Enfoque obsesivo hacia las necesidades de sus clientes.

- Trabajo en equipo.

- Responsabilidad.

- Comunicación efectiva.

- Iniciativa.

- Sólida destreza en el uso de las herramientas y técnicas de análisis de datos.

- Productividad.

- Solucionador de problemas.

- Conocimientos técnicos.

\section{Control Interno}

Las percepciones del significado de control interno son muy diferentes, dependiendo del usuario, preparador, auditor o dirección. Sotomayor (2016), sostiene que: "para algunos usuarios, control interno se refiere a los procedimientos de conciliaciones y autorizaciones; para otros, pudieran ser los controles relativos a fraude; y para otros, ser solo políticas y procedimientos establecidos en las empresas" (p.1).

El control interno es una herramienta de la administración para mitigar factores de riesgo y así prevenir o detectar representaciones erróneas de importancia relativa.

El Marco Integrado de Control Interno propuesto por COSO III -The Committee of Sponsoring Organizations of the Treadway Commission (2013) provee un enfoque integral y herramientas para la implementación de un sistema de control interno efectivo y en pro de la mejora continua. Define el control interno, "como un proceso llevado a cabo por el consejo de administración, la dirección y el resto del personal de una entidad, diseñado con el objeto de proporcionar un grado de seguridad razonable en cuanto a la consecución de objetivos relacionados con las operaciones, la información y el cumplimiento. (p.3)

De esta manera, el control interno se convierte en una función inherente a la administración, integrada al funcionamiento organizacional y a la dirección institucional y deja, así, de ser una función que se asignaba a un área específica de una empresa.

Se puede decir, que el control interno lo conforman un conjunto de procedimientos, políticas, directrices y planes de organización, los cuales tienen por objeto asegurar una eficiencia, seguridad y orden en la gestión financiera, contable 
y administrativa para salvaguardar los activos, fidelidad del proceso de información, registros y el cumplimiento de políticas definidas.

Para Racines (2018), relator Internacional experto en Auditoría, la primera misión de los controles es: “alcanzar los objetivos de rentabilidad, maximización de ingresos y control de costos \& gastos en la organización y luego está la mitigación de los riesgos" (p.5).

La efectividad de los controles se determina de la gestión de riesgos que se deriva, lo que le permite a las empresas identificar cuáles son los productos o actividades más relevantes y los riesgos que conlleva cada uno de ellos. (Racines, 2018)

\section{Riesgo}

Según la PM-BOK Guide, citada por Ealde Business School en su artículo Gestión de riesgos (2016), un riesgo es aquel "evento o condición incierta que, si se produce, tiene un efecto positivo o negativo en los objetivos de un proyecto" (p.1).

La gestión de riesgo está vinculada en todo momento con los objetivos estratégicos del negocio, en los que debe haber una planificación de los recursos (financieros, capital humano, tecnología), que conlleve a una mayor eficiencia y efectividad, asociados a menores costos.

En la implementación del proceso de gestión de riesgos se deben establecer mecanismos de control, la matriz de riesgos constituye uno de ellos y facilita el control sobre aquellos que son más críticos y la correcta gestión de los recursos para mitigar cada uno de ellos con determinadas actuaciones. La matriz de riesgos evalúa si la gestión de cada uno de esos riesgos está siendo efectiva y cómo afecta el cumplimiento de los objetivos estratégicos.

\section{Gobierno Corporativo}

Para Gloval Corporate Governance Forum (2010), el gobierno corporativo es "el sistema por el cual se dirigen y controlan las compañías" (p.1). Implica un equilibrio de poder entre tres grupos corporativos claves: la junta directiva, que se encarga del monitoreo, la supervisión y la dirección de la compañía; los accionistas, que invierten sus fondos en las acciones de la entidad y, por lo tanto, tienen el derecho a elegir y eventualmente remover directores; y la gerencia de la organización, la cual es elegida por la junta para que maneje la compañía en sus labores del día a día.

Cada día son mayores los retos que enfrentan las organizaciones para sobrevivir en el mercado, en donde deben mantener una estructura eficiente de control interno y gobierno corporativo, lograr eficacia y eficiencia en sus procesos, reducir sus costos, atender las tendencias en los niveles de automatización y ajustarse a los requerimientos que exige la normativa, así como gestionar proactivamente los riesgos. (Gloval Corporate Governance Forum, 2010)

Como lo indica Flores (2019), es la integración y función de los órganos de la empresa que se encarga de dirigir y controlar que contribuyan al logro efectivo de los objetivos, y que guíen las obligaciones, responsabilidades de los miembros de la Alta Dirección de la compañía. También definen la forma en que éstas operan, son controladas e interactúan con sus accionistas y demás partes interesadas del negocio. (p.61)

Como lo define el Código de Mejores Prácticas Corporativas -CMPC- (2010) el gobierno corporativo, funciona bajo el contexto de identificación, administración y el control de los riesgos a que están sujetas las empresas, se debe transformar en un elemento vital e impulsor para coadyuvar en "el sistema, bajo el cual las sociedades son dirigidas y controladas. (p.10) lo que trasciende favorablemente en crear valor y lograr una mayor confianza y reconocimiento por parte de los accionistas actuales y potenciales. 


\section{METODOLOGÍA}

\section{Problema de Investigación:}

¿Cuál es la importancia para las empresas del sector privado contar con una unidad de auditoría interna?

\section{Objetivos}

El objetivo general es determinar el aporte que realiza una unidad de auditoría interna en la organización de una empresa, así como las competencias y la formación con la que debe contar el personal que la integra. Asimismo, los objetivos específicos de esta investigación, buscan determinar la percepción que tienen los empresarios y profesionales en contaduría pública respecto a la creación de una unidad de auditoría interna en la empresa, con la formación del personal que la integra y de las competencias generales y específicas que debe reunir este profesional.

\section{Diseño Muestral}

Para la investigación se requiere de una estratificación previa a la toma de encuesta, para determinar el espacio muestral. Sapag \& Sapag (2014), señala que se debe de seleccionar a los individuos que consumen el bien o servicio a evaluar. Por otra parte, el cálculo del tamaño de la muestra es fundamental para la confiabilidad de los resultados y considera: $n=\left(\boldsymbol{\sigma}^{2} * \mathbf{Z}^{2}\right) / e^{2}$ donde, $\mathrm{n}$ es el tamaño de la muestra, $\boldsymbol{\sigma}$ la desviación estándar (puede ser referencia de otros estudios), $Z$ el valor crítico de una distribución normal para un nivel de confianza dado y el valor de error máximo permitido. (p. 93), con un nivel de confianza de 95\% y un margen de error de 2,5\%. El resultado de n (tamaño de la muestra) es de 140 .

\section{Variables:}

Se define una estructura taxonómica para la comprensión de las variables con las que se propone abordar el tema objeto de estudio, que fundamente el instrumento de recolección de datos. Para esta investigación se aplicó un cuestionario como instrumento utilizado para responder la estructura definida en las variables. A continuación, se exponen las tablas de variables $\mathrm{N}^{\circ} .1,2$ y 3; que incluyen cada objetivo específico con su respectiva pregunta de abordaje en la encuesta, así como la descripción de las variables asociadas.

\section{Tabla 1}

Objetivo específico $N^{\circ} 1$.

Evaluar la percepción de los empresarios y profesionales en contaduría pública con respecto a la inclusión de una unidad de auditoría interna en una empresa

\begin{tabular}{|c|c|c|c|}
\hline Variable & $\begin{array}{c}\text { Conceptualización de } \\
\text { la variable }\end{array}$ & $\begin{array}{c}\text { Instrumentalización e } \\
\text { ítems de la variable } \\
\text { (cuestionario) }\end{array}$ & $\begin{array}{c}\text { Operacionalización } \\
\text { de la variable }\end{array}$ \\
\hline $\begin{array}{l}\text { Percepción de las } \\
\text { competencias del } \\
\text { auditor interno }\end{array}$ & $\begin{array}{l}\text { La percepción de un auditor } \\
\text { interno, está enfocada a dar } \\
\text { un acompañamiento a la } \\
\text { organización con conocimiento } \\
\text { del giro de la misma. } \\
\text { Las competencias de un auditor } \\
\text { interno es la aptitud profesional } \\
\text { para el desarrollo eficaz en sus } \\
\text { responsabilidades profesionales }\end{array}$ & $\begin{array}{l}\text { ¿Cuáles son las causas o razones } \\
\text { de no contar en su organización } \\
\text { con una Unidad de Auditoría } \\
\text { Interna? } \\
\text { ¿Conoce la importancia para su } \\
\text { empresa de crear un Departamento } \\
\text { de Auditoría Interna como unidad } \\
\text { de control y riesgo? } \\
\text { ¿Qué funciones le asignaría en } \\
\text { la organización al personal que } \\
\text { integra a la Unidad de Auditoría } \\
\text { Interna? }\end{array}$ & $\begin{array}{l}\text { Esta variable se mide mediante } \\
\text { tres ítems abiertos: } \\
\text { Razones para el uso de la } \\
\text { auditoría interna } \\
\text { Importancia de la auditoría } \\
\text { interna } \\
\text { Funciones para la auditoría } \\
\text { interna }\end{array}$ \\
\hline
\end{tabular}

Fuente: elaboración propia. 


\section{Tabla 2}

Objetivo específico $\mathrm{N}^{\circ} 2$

Indagar cual es la importancia que tiene la formación académica para los empresarios al reclutar el capital humano que conforma la unidad de auditoría interna.

\begin{tabular}{|c|c|c|c|}
\hline Variable & $\begin{array}{c}\text { Conceptualización } \\
\text { de la variable }\end{array}$ & $\begin{array}{c}\text { Instrumentalización } \\
\text { e ítems de la variable } \\
\text { (cuestionario) }\end{array}$ & $\begin{array}{c}\text { Operacionalización } \\
\text { de la variable }\end{array}$ \\
\hline $\begin{array}{l}\text { Formación académica en } \\
\text { la carrera de Contaduría } \\
\text { Pública }\end{array}$ & $\begin{array}{l}\text { Los estudios necesarios en la } \\
\text { formación de un auditor interno } \\
\text { a nivel universitario como } \\
\text { pilar técnico, capacitación } \\
\text { complementaria en aplicaciones } \\
\text { prácticas de la normativa y } \\
\text { de tecnología de su campo } \\
\text { profesional. }\end{array}$ & $\begin{array}{l}\text { En su representada, el o los } \\
\text { auditores internos ¿̇cuentan con los } \\
\text { títulos idóneos y experiencia en el } \\
\text { campo de la auditoría? } \\
\text { A su criterio, ¿ ¿ Cuál debiera ser } \\
\text { la formación que deban tener los } \\
\text { estudiantes de Contaduría Pública } \\
\text { para estar a cargo de una Unidad } \\
\text { de Auditoría Interna? }\end{array}$ & $\begin{array}{l}\text { Esta variable se mide mediante dos } \\
\text { ítems abiertos: } \\
\text { Experiencia en el campo de la } \\
\text { auditoría. } \\
\text { Formación académica en el área } \\
\text { de la auditoría. }\end{array}$ \\
\hline
\end{tabular}

Fuente: elaboración propia.

\section{Tabla 3}

Objetivo específico $\mathrm{N}^{\circ} 3$

Establecer cuáles son las exigencias de los empresarios ante las competencias generales y específicas que debe reunir un profesional en auditoría interna.

\begin{tabular}{l|l|l|l|l} 
Variable & \multicolumn{1}{c|}{$\begin{array}{c}\text { Conceptualización } \\
\text { de la variable }\end{array}$} & $\begin{array}{c}\text { Instrumentalización } \\
\text { e ítems de la variable } \\
\text { (cuestionario) }\end{array}$ & $\begin{array}{c}\text { Operacionalización } \\
\text { de la variable }\end{array}$ \\
\hline $\begin{array}{l}\text { Profesional de auditoría } \\
\text { interna }\end{array}$ & $\begin{array}{l}\text { Disponer de competencias de } \\
\text { un auditor interno, como: aptitud } \\
\text { para aplicar conocimientos, } \\
\text { habilidades obtenidas en } \\
\text { su formación académica y } \\
\text { en el ejercicio profesional } \\
\text { (experiencia). }\end{array}$ & $\begin{array}{l}\text { En su organización ítstá dispuesto } \\
\text { de contar con personal calificado } \\
\text { externo para que realice las } \\
\text { funciones de la auditoría interna en } \\
\text { su empresa? }\end{array}$ & $\begin{array}{l}\text { Ítem abierto: } \\
\text { Formación académica y } \\
\text { experiencia laboral en el área de } \\
\text { la auditoría interna }\end{array}$ \\
\hline
\end{tabular}

Fuente: elaboración propia.

\section{Instrumento}

Esta investigación se realiza con la finalidad de cotejar conceptos, teoría, en el campo de la auditoría interna y a partir de la aplicación de un cuestionario como herramienta de recolección de información que permita triangular los resultados de las impresiones de los empresarios de la funcionalidad de una unidad de auditoría interna, con lo que describen autores que versan sobre el tema.

El instrumento fue sometido a una revisión por parte de las autoridades institucionales como mecanismo de validación, y es a partir de su aplicación que se pretende explorar el sentir y conocimiento del empresario, respecto al desarrollo de su actividad económica, ubicación, años de funcionamiento de la empresa, existencia y años de creación de una unidad de auditoría interna, así como recolectar su opinión acerca de los atestados idóneos, experiencia, del capital humano que las conforman.

Valorar si los costos que demandan su presencia en la organización son relevantes versus la importancia y alcance que representa en la salvaguarda de sus activos y presentación razonable de los saldos que muestran sus principales estados financieros. 
Conocer cómo hace las organizaciones que no cuentan con una unidad de auditoría interna para resolver los asuntos inherentes a ella.

Así, como conocer de la importancia que dan los empresarios al profesional en auditoría y que éste incorpore en la planificación de la auditoría interna la estrategia organizacional, la evaluación de gestión del riesgo y la necesidad de contar con Gobierno Corporativo.

\section{Procedimientos}

Las empresas del sector privado entrevistadas en el estudio, ascendieron a 140 (tamaño de la muestra). Los entrevistados se caracterizan por su grado académico de Doctorado y Licenciatura con puestos en Auditoría, Contabilidad, Supervisor de Control interno, principalmente, y lo que se busca con esta muestra es medir actitudes y comportamientos esperados del mercado, por lo que resulta conveniente una técnica estructurada, que se caracteriza por facilitar respuestas breves, simples, específicas y con opciones limitadas.

Por lo que, con el diseño del cuestionario de la investigación, se busca recolectar información de los responsables del área de auditoría interna, empresarios (responsables de la toma de decisiones estratégicas en cuanto a contratación de profesionales en el campo de la auditoría interna), y estudiantes, durante un momento determinado.

Las personas entrevistadas del sector privado, se localizaron a través de los correos electrónicos facilitados de la base de datos del Instituto de Auditores Internos de Costa Rica.

En la investigación se utilizaron como base, un enfoque cuantitativo para resolver el problema planteado a lo largo de los objetivos lo que permite identificar las razones, factores, limitantes de no contar con una unidad de auditoría interna. Para lo que se emplea un cuestionario conformado por 20 preguntas abiertas y cerradas. El instrumento fue validado ante un grupo de profesionales en Contaduría Pública, previo a su aplicación, dentro del campus universitario.

Se aplica el enfoque cuantitativo por medio de la recolección y análisis de datos de los resultados obtenidos con la aplicación del instrumento "encuesta" a los empresarios y profesionales en la disciplina de Contaduría Pública del sector privado. Se analiza la opinión y el conocimiento que tienen los encuestados respecto de las competencias profesionales de un auditor interno, conceptos teóricos de: auditoría, control interno, gestión de riesgos, gobierno corporativo. Así como, el reconocimiento del negocio y los principales aportes que brinda una unidad de auditoría interna a la alta gerencia.

\section{ANÁLISIS DE RESULTADOS}

Como resultado del proceso de tabulación de los datos provenientes de la aplicación del instrumento de recolección de la información "encuesta", se tienen:

A la pregunta, en donde se solicita al entrevistado que indique su grado académico y especialidad, $76 \%$ de los entrevistados son profesionales en auditoría (Contaduría Pública) y $24 \%$ provienen de otros campos profesionales. Se consultó: ¿Cuál es la actividad principal que desarrolla la empresa para la cual usted representa o labora? Se obtuvo como respuesta que los encuestados provienen de empresas de: servicios hospitalarios, servicios financieros, intermediación bursátil, empresas de mensajería, empresas de capacitación y formación profesional, profesionales independientes, "outsourcing", eléctricos, agroindustrial, abastecimiento de combustibles, sociedades administradoras de fondos de inversión, de fondos de pensiones, comercializadores de productos agrícolas, generadoras de electricidad entre otras.

Ante la consulta, de cuánto tiempo han laborado en la organización. Se identificó que 94,4 \% de los entrevistados laboran en organizaciones que cuentan con un departamento de auditoría interna, caracterizado por profesionales en área de Contaduría Púbica y Administración de Negocios, con el grado académico de licenciatura, maestría y doctorado.

Como respuesta a la pregunta: ¿Cuánto tiempo tiene de funcionar la empresa? El 83,3 \% de las empresas fueron fundadas hace más de 20 años. Del $100 \%$ de los consultados $50 \%$ señala que ésta unidad tiene más de 20 años de constituida en sus organizaciones, 9,4\% tienen entre 5 a 10 años y $3,9 \%$ de 1 a 5 años.

El 5,6\% de las empresas manifestaron que no cuentan con una unidad de auditoría interna, justifican su ausencia por razones de costo, como lo son: salarios, cargas sociales, y a la falta de claridad respecto a la relación costo/beneficio de disponer de un departamento de auditoría. 
Como respuesta a la pregunta: ¿En qué zona geográfica se encuentra su organización?

El $83.2 \%$ de los entrevistados se localizan geográficamente en la provincia de San José, 2,8 \% en Alajuela, 5,6\% en Cartago, 5,6 \% en Heredia y 2,8 \% en Guanacaste.

A la pregunta: ¿Conoce la importancia para su empresa de crear un Departamento de Auditoría Interna como unidad de control y riesgo? El $67 \%$ de los entrevistados considera que, Si es importante contar con un departamento de Auditoría Interna y lo fundamentan en el papel que ésta destaca en los procesos de revisión del control interno y la evaluación de riesgo, como variables que coexisten dentro de la organización.

Los consultados que tienen dentro de sus organizaciones un departamento de auditoría interna, tienen claridad de las competencias de ésta, respecto a las funciones propias de una auditoría externa. Por lo que consideran que la auditoría interna debe de estar conformada con personal idóneo y calificado.

A la pregunta: ¿De qué manera gestionan los asuntos propios de una unidad de auditoría interna si no cuentan con esa figura? El $88.8 \%$ de los encuestados señalan que no atienden las gestiones propias de una unidad de auditoria interna, $5.6 \%$ indican que lo realizan mediante el auditor interno de la empresa, $2,8 \%$ lo realiza a través del contador de la empresa y finalmente $2,8 \%$ menciona que los atiende mediante el auditor externo.

Los consultados señalan que recurren a la contratación de profesionales en el campo de auditoría externa, mediante la modalidad de outsourcing y sólo para trabajos especiales.

Para los casos en los que no cuentan con una unidad de auditoría interna, mecionan que la gestión de los asuntos propios, se canalizan a través del área contable de la empresa o mediante los auditores externos.

A la pregunta: ¿Cuál debe de ser la formación que deban de tener los estudiantes de Contaduría Pública, para estar a cargo de una unidad de auditoría interna? El 100 \% de los entrevistados consideran que los egresados graduados deben de contar con la siguiente formación:

- Conocimiento teórico y práctico de las NIC (Normas Internaciones de Contabilidad), NIIFF FULL (Normas Internacionales de Información Financiera), NIIF para PYMES (Norma Internacional de Información Financiera para Pequeñas y Medianas Entidades), NIAS (Normas Internacionales de Auditoría), Nuevos principios de contabilidad.

- Experiencia académica/laboral y estudios de casos.

- Conocimiento en auditoría gubernamental.

- Conocimiento en la evolución y aplicación del control interno (COSO).

- Evaluación de riesgo.

- Conocimiento y experiencia, en el uso de Software de minería de datos, para análisis y evaluación de fraude.

- Gestión y gobierno corporativo

- Tecnología de Información.

- Confección de estados financieros, redacción de políticas contables y notas a los estados financieros.

- Elaboración de presupuestos.

- Experiencia previa en despachos de auditoría externa.

A la pregunta: ¿Dónde posicionaría a la función de la auditoría interna dentro de la organización?, el 100\% de los encuestados ubican a la unidad de auditoría interna dentro del organigrama como una unidad staff, con dependencia directa de la Junta Directiva y a su vez consideran que estas unidades deben aportar valor, participar en la planificación estratégica, en la evaluación de riesgos, actuar como una auditoría operativa de cumplimiento, asesora, consultora, fiscalizadora, investigadora, analítica en la labor de determinar si los sistemas, procedimientos, evaluación de procesos y obtención de resultados sean efectivas con sus respectivas recomendaciones para la toma de decisiones. Asimismo, el monitoreo de riesgos y controles de la organización. 
El $100 \%$ de los entrevistados indican que la gestión de riesgo se da a través de un marco integral inmerso en el plan de auditoría; con la aplicación de metodologías, planes, evaluaciones, discusiones de alto nivel, con personal especializado en riesgos y aplicación de modelos. Además, a través del diseño de políticas y procedimientos bien definidos sobre la forma de realizar el negocio. También externan la necesidad de crear una unidad de gestión de riesgo, dentro de la organización. Los consultados consideran de suma importancia que la planificación de la auditoría influye en la eficacia y eficiencia de la unidad.

Ante la pregunta de conocer el concepto de gobierno corporativo y que, ¿aplica a todas las empresas, sin importar el volumen de ventas, número de empleados, origen del capital o cualquier otra característica que clarifique a la organización? El 97 \% de los consultados responden tener conocimiento del significado y aplicación de Gobierno Corporativo en el mundo empresarial. El 66, 7\% de los entrevistados confirman que en sus organizaciones cuentan con una estructura implementada de gobierno corporativo, que les permite organizar, dirigir, gestionar, controlar el rumbo de la empresa.

Al consultarle a los entrevistados su opinión respecto a las competencias que deba tener un auditor interno que se expone en la tabla $\mathrm{n}^{\circ} 4$, contestaron lo siguiente:

\section{Tabla 4}

Competencias de un auditor interno

\begin{tabular}{l|c}
\multicolumn{1}{c|}{ Competencia } & Entrevistados \\
\hline $\begin{array}{l}\text { Conocimiento de la organización a auditar mediante } \\
\text { revisiones financieras, operativas y de cumplimiento }\end{array}$ & 13 \\
\hline $\begin{array}{l}\text { Proactivo en el análisis del entorno, control interno, } \\
\text { gestión y evaluación del riesgo }\end{array}$ & 26 \\
\hline $\begin{array}{l}\text { Profesional con criterio sólido en el desempeño como } \\
\text { asesor, consultor y fiscalizador }\end{array}$ & 7 \\
\hline $\begin{array}{l}\text { Experiencia en formulación y evaluación de indicadores } \\
\text { de gestión }\end{array}$ & 4
\end{tabular}

Fuente: elaboración propia.

\section{DISCUSIÓN}

1. Según la respuesta al instrumento, los empresarios perciben que una unidad de auditoría interna debe agregar valor a la organización, respuesta que va muy de la mano con la teoría; señalan como son las siguientes formas o maneras en que el auditor interno puede agregar valor a la organización como las siguientes:

- A través de la conveniencia de realizar actividades de consultor interno, en donde juega un papel destacado en la conformación de la estructura de gobierno corporativo y el binomio que se da entre el control interno y la gestión de riesgos.

- En el desempeño de nuevas funciones, en donde fortalezca los niveles de confianza de los usuarios, administración, consejo directivo.

- Innovación en temas y prácticas emergentes en la gestión.

- Evaluación de áreas de gestión, que contribuyan a identificar puntos fuertes, áreas de mejoras, análisis de eficiencia.

- Desempeñar un papel activo, en el análisis de: riesgos inherentes, factores de riesgo, valoración de riesgos, controles clave, indicadores de control, revisión de procesos, factores de éxito.

- Estar atento a los cambios en la cultura de gestión empresarial, mediante una constante actualización y valorar la importancia de nuevos instrumentos de gestión. 
Como lo señala Estupiñán (2016), la auditoría interna puede proveer aseguramiento en tres áreas:

a.) Procesos de gestión o administración de riesgos, tanto en su diseño y cómo que tan bien están trabajando.

b.) Gestión o Administración de aquellos riesgos clasificados como "claves", incluyendo efectividad de los controles y otras respuestas a éstos, y

c.) Confiabilidad y evaluaciones apropiadas de riesgos y reportes de riesgo y estatus de controles. Servicios que presta la auditoría. (p.240)

2. Los empresarios consideran necesaria la labor que realizan las unidades de auditoría interna y señalan que representan un costo relevante en la organización y a su vez reflexionan que, si a éstas se les brinda personal y presupuesto contribuirían en las labores de control interno, gestión del riesgo y gobierno corporativo. Consideran relevante que el auditor interno conozca del giro de hacer negocios y que aporten valor en el desempeño de sus funciones.

De acuerdo con Silva (2017), el auditor interno, debe actuar como un promotor de cambio en las empresas, de manera que permita garantizar un proceso efectivo en la revisión de reprocesos, duplicidad de funciones, generación de reportes, que demuestran los beneficios que generará su labor.

Asimismo, en forma acertada menciona Silva (2017), que el auditor interno debe ser un agente de cambio, de calidad y lograr preservar los estándares que establecen las organizaciones para detectar y fortalecer los controles correspondientes.

3. Los empresarios informan que cuentan con una unidad de auditoría interna debidamente conformada dentro de sus posibilidades económicas y manifiestan que variables como control interno y gestión de riesgos coexisten dentro del principio de negocio en marcha, por lo que las personas profesionales en Contaduría Pública deben de estar a la vanguardia del conocimiento de los aspectos sensibles tanto interno como externo.

4. A través del contraste de lo consultado a los entrevistados respecto a los que ellos esperan de los egresados en la formación académica de Contaduría Pública y los que se ofrecen en la malla curricular se evidencia una concordancia en los conocimientos y aplicaciones del campo profesional.

5. De acuerdo con la respuesta de los entrevistados en contraste con la revisión de la malla curricular de la carrera de Contaduría Pública se observa que existe una concordancia entre los requerimientos o exigencias del sector empresarial costarricense consultado, los entrevistados opinaron respecto a la formación académica del egresado en Contaduría Pública; que va muy de la mano con las incorporaciones de cursos a la nueva malla curricular propuesta ante el órgano nacional acreditador, con programas como: Inglés técnico para contaduría, normativa contable internacional, negociones internacionales, asesoría fiscal, control interno y gestión de riesgo, legislación para contadores, práctica universitaria supervisada, seminario de ética en el ejercicio profesional, auditoría forense.

6. Los entrevistados consideran que las empresas van encaminadas a ser dirigidas y controladas bajo el sistema de un gobierno corporativo, que tenga un papel determinante en la solución de desacuerdos y conflictos entre sus componentes, pero sobre todo a mantener, impulsar y renovar a la organización del mercado interno y externo.

7. Se desprende del análisis investigativo que el auditor interno debe desarrollar de manera eficiente y efectiva, medidas integrales de control interno acorde con el entorno operativo de la organización, procurar mitigar riesgos a niveles aceptables y acompañar mediante su labor consultiva el proceso de toma de decisión y al gobierno corporativo de la organización.

8. Las firmas externas no profundizan en el gobierno de la organización, en la gestión de riesgos ni en las operaciones de control interno; a menos que el objetivo y el rol así lo requieran. Ese asesoramiento y observaciones inmediatas y preventivas son las que agregan valor a una organización, labores que están al alcance, si la organización cuenta con un profesional en Contaduría Pública, en el área de auditoría interna. 
De los resultados obtenidos en la investigación se pueden contrastar los pensamientos de los entrevistados con lo que menciona Mendívil (2016) al considerar que la Unidad de Auditoría Interna debe de estar conformada con personal profesional. Además, se adiciona las acepciones de Sandoval (2012); en donde se señala que se debe de verificar que la información financiera, administrativa y operacional debe ser confiable, veraz y oportuna.

Acorde con las exigencias actuales el Instituto de Auditores señala el enfoque de trabajo de procesos alineado con el control interno, gestión de riesgo y gobierno corporativo.

El marco normativo que regula el quehacer profesional de un auditor interno ha evolucionado de las Normas de Auditoría Generalmente Aceptadas (NAGAS) a las Normas Internacionales de Auditoría (NIAS) en donde juega un papel destacado las competencias y habilidades blandas.

\section{CONCLUCIONES}

Se recomienda la creación de la unidad de auditoría interna en las organizaciones en el caso de las empresas que no cuenten con la misma, para que vigile las operaciones, actuación de la administración y cumplan con la labor de vigilancia reconocida en el mundo de los negocios y adquiera mayor importancia ante la necesidad de proteger a los dueños de los malos manejos que pudiera hacer la administración y que garantice la veracidad de las actividades jurídicas y financieras.

La labor de la auditoría interna debe ser desempeñada por personas calificadas, comprometidas con su independencia, escepticismo profesional, conducta ética en el ejercicio profesional.

Los profesionales en Contaduría Pública deben tener disposición a estar actualizados profesionalmente, que los mantenga a la vanguardia en el proceso de agregar valor en la empresa.

Dotar a las unidades de auditoría interna de recursos suficientes para su adecuado desempeño dentro de la organización.

Se recomienda a las organizaciones encargadas de la formación académica universitaria de los contadores públicos, monitorear con cierta periodicidad el mercado laboral para conocer e incorporar las nuevas exigencias del sector empresarial.

Los profesionales en Contaduría Pública, para dar inicio y progresar en las labores de auditoría interna, deben comenzar por tener u obtener las competencias y herramientas requeridas para auditar. El incursionar en temas innovadores para la prestación del servicio, proporciona ayuda en la dirección y atención de las empresas, en temas críticos como: control interno, gestión del riesgo y gobernanza corporativa.

Se recomienda al profesional en Contaduría Pública la capacitación permanente en su campo para que goce de conocimientos (competencias técnicas) y competencias de gestión (conductuales), para el adecuado desempeño de sus funciones. 


\section{REFERENCIAS}

Alles, M. (2015). Diccionario de competencias. 2 ed. Gránica, S.A.

Auditool. (2016). Competencias fundamentales para el éxito como auditor interno. /www.auditool.org/blog/auditoríainterna/4779-competencias-fundamentales-para-el-exito-como-auditor-interno.

Auditool. (2016). Evaluación del Control Interno y sus Componentes en la Auditoría de Estados Financieros. www.auditool. org/blog/auditoríaexterna/3583 -evaluación-del-control-interno-y-sus-componentes- en-la-auditoría deestados-financieros.

Colombia (2006) Guía de Administración del Riesgo. facartes.unal.edu.co/calidad/docs/guia_riesgos.pdf.

Committee of Sponsoring Organizations of the Treadway. COSO (2013). COSO III. EEUU

EALDE (2016). Gestión de Riesgos. www.ealde.es/fundamentos-la-gestion-riesgos/.

Estupiñán Gaitán, R. (2016). Administración de riesgos E.R.M. y la auditoría interna, 2 ed. Ecoe Ediciones. elibro.net/es/ ereader/ufidelitas $/ 70422$ ?page $=239$

Flores Mendoza, R. L. y Cervantes Penagos, M. Á. (2019). Evaluación del desempeño del Gobierno Corporativo. Instituto Mexicano de Contadores Públicos. elibro.net/es/ereader/ufidelitas/124949?page=61

Frett, N. (2015). Lo que todo auditor interno debe saber. nahunfrett.blogspot.com/2015/03/lo-que-todo-auditor-internodebe-saber.html.

Global Corporate Governance Forum (2010). Herramienta 4: Resolución de Conflictos de Gobierno Corporativo. www.ifc.org/ wps/wcm/connect/topics_ext_content/ifc_external_corporate_site/ifc+cg/resources/toolkits+and+manuals/ herramienta $+4++$ resolucion + de+conflictos + de+gobierno+corporativo.

Instituto Interno de Auditores (2013). Control Interno-Marco Integrado. doc.contraloria.gob.pe/Control-Interno/ Normativa_Asociada/coso_2013-resumen-ejecutivo.pdf.

Instituto Interno de Auditores (2017). Perspectivas y percepciones globales. Auditoría interna y auditoría externa. e na.theiia. org/translations/ ublicDocuments /GPI-Distinctive-Roles-in-Organizational- Governance-Spanish.pdf

International Federation of Accountants IFAC. (2016). Normas de Auditoría para atestiguar, revisión y otros servicios relacionados. México: Instituto Mexicano de Contadores Públicos.

Mendívil, V. (2016). Elementos de Auditoría. 7 ed. Cengage Learning Editores S.A. de C.V.

Pérez, I., Useche, O. \& Quirós, R. (2015). Transformación de la Auditoría Interna. Boletín de Consultoría Gerencial.

Racines, F. (2018). Curso de Certificado de Control COSO. Obtenido de https://iaichile.org/noticias/ finaliza-con-éxitocurso-de- certificado-en-control-interno-coso/.

Sandoval, H. (2012). Introducción a la Auditoría. Red Tercer Milenio S.C.

Sapag, N. \& Sapag R. (2008). Preparación y Evaluación de Proyectos. Colombia. Editorial Mc Graw Hill.

Silva Villavicencio, R. A. Rueda de León Contreras, R. S. y Tapia Iturriaga, C. K. (2017). Auditoría interna: perspectivas de vanguardia. Instituto Mexicano de Contadores Públicos. elibro.net/es/ereader/ufidelitas/116357?page $=42$

Silva Villavicencio, R. A. Rueda de León Contreras, R. S. y Tapia Iturriaga, C. K. (2017). Auditoría interna: perspectivas de vanguardia. Instituto Mexicano de Contadores Públicos. elibro.net/es/ereader/ufidelitas/1 16357?page=42.

Sotomayor, R. (2016). Evaluación del control interno y sus componentes en la auditoría de estados financieros. Director de Auditoría Moore Stephens Sotomayor Elías, S.C., Oficina Hermosillo/Miembro de la CONAA

Universidad Cooperación Internacional (2014). Caso Enron. http://www.ucipfg.com/Repositorio/MAES/MAES04/BLOQUE-ACADEMICO/Unidad-3/lecturas/Caso_Enron_2.pdf tuning.unideusto.org/tuningal/index. php?option $=$ content\&task $=$ view\&id $=230 \& I$ temid $=259$ 